\title{
"FREDI NO MUNDO DA RECICLAGEM": JOGO EDUCACIONAL DIGITAL PARA CONSCIENTIZAÇÃO DA IMPORTÂNCIA DA RECICLAGEM
}

\author{
Angélica Alessandra Skalee - angiiskalee@gmail.com - UFSM/FW \\ Silvana Kliszcz - silvana@websetbrasil.com - UFSM/FW \\ Fábio José Parreira - fabioparreira@gmail.com - UFSM/FW \\ Sidnei Renato Silveira - sidneirenato.silveira@gmail.com - UFSM/FW
}

Resumo. Este artigo apresenta o desenvolvimento de um protótipo de jogo educacional digital - "Fredi no Mundo da Reciclagem", para séries iniciais do Ensino Fundamental, buscando conscientizar as crianças sobre a importância da reciclagem no dia a dia, dentro do contexto da Educação Ambiental. O principal resultado consistiu na implementação de um protótipo de jogo utilizando-se a ferramenta Construct 2 e a validação deste jogo em escolas de Ensino Fundamental, o qual poderá ser utilizado pelos professores para abordarem os conteúdos relacionados ao meio ambiente.

Palavras-Chave: Jogos Educacionais Digitais; Educação Ambiental, Infomática na Educação.

\section{“FREDI NO MUNDO DA RECICLAGEM": DIGITAL EDUCATIONAL GAME TO CONSCIOUSNESS THE IMPORTANCE OF RECYCLING}

\begin{abstract}
This paper presents the development of a prototype of digital educational game - "Fredi no Mundo da Reciclagem", for the early grades of elementary school, seeking to educate children about importance of recycling on a daily basis, within the context of environmental education. The main result is the implementation of a game prototype using the Construct tool 2 and the application of this game on a school education Key, which can be used by teachers to address the content related to the environment.
\end{abstract}

Keywords: Digital Educational Games; Environmental Education, Computer in Education.

\section{INTRODUÇÃO}

A inserção da Informática na Educação requer que professores e agentes educacionais possuam conhecimento de ferramentas que podem ser usadas na prática educacional, além de explorar os instrumentos computacionais, a fim de obter maior desempenho educacional com os mesmos (COX, 2003). Entre estas ferramentas, encontram-se os jogos educacionais digitais.

Os jogos, para fins educacionais, devem ter seu objetivo bem definido para o sucesso da aprendizagem, oferecendo auxílio ao conteúdo das disciplinas a serem trabalhadas ou, ainda, desenvolver habilidades que ampliem nos alunos as capacidades intelectual e cognitiva. Os estudantes desenvolvem diversas habilidades, além de ser um 
ambiente de motivação a aprendizagem, o que torna o jogo um material didático rico (GROS, 2003 citado por SAVI; ULBRICHT, 2008).

O jogo, no ambiente escolar, torna a aprendizagem mais atrativa e desafiadora, trazendo benefícios não somente aos alunos como também aos professores, que podem utilizar desse recurso como forma de diversão e aprendizado, transformando simples assuntos do dia a dia das crianças em grande conhecimento de forma prazerosa, explorando a imaginação e a criatividade de seus jogadores (PARREIRA et. al., 2016).

Neste contexto, o principal objetivo deste trabalho foi a implementação de um protótipo de jogo educacional digital, denominado "Fredi no Mundo da Reciclagem", voltado às séries iniciais do Ensino Fundamental, para alunos de 7 (sete) a 9 (nove) anos de idade, para enfatizar a importância da reciclagem no dia a dia. Acredita-se que é importante apresentar às crianças, nas séries iniciais do Ensino Fundamental, informações sobre a preservação do meio em que vivem, trabalhando de forma lúdica e divertida, complementando o ensino tradicional.

No mundo atual, a conscientização sobre o meio ambiente é de fundamental importância, para que os seres humanos tenham consciência de que a qualidade de vida desejada depende do seu cuidado com o meio em que vivem. O ser humano é dependente do meio ambiente, pois precisa do mesmo para sua sobrevivência. Com a promulgação da Lei $N^{\circ}$ 9.795, de 27 de abril de 1999, que instituiu a Politica Nacional de Educação Ambiental, ficou estabelecido que a Educação Ambiental (EA) deve se fazer presente no ensino privado e público, englobando a Educação Fundamental, etapa escolar para a qual foi desenvolvido o protótipo do jogo (BRASIL, 1999).

Para dar conta desta proposta, este artigo está estruturado como segue: a seção 2 apresenta alguns conceitos sobre Jogos Educacionais Digitais. A seção 3 apresenta a implementação e validação do protótipo de jogo desenvolvido. Encerrando o artigo, são apresentadas as considerações finais, as referências empregadas e os anexos.

\section{JOGOS EDUCACIONAIS}

Os jogos, como instrumentos lúdico-didáticos, inserem-se no âmbito educacional possibilitando a liberação de tensões, desenvolvendo habilidades, criatividade, espontaneidade, entre outras características, que podem tornar os processos de ensino e de aprendizagem mais interessantes e atrativos (ALVES et al. 2010 citados por REIS et al., 2012).

Os jogos digitais podem ser definidos como ambientes atraentes e interativos, que capturam a atenção do jogador ao oferecer desafios que exigem níveis crescentes de destreza e habilidades, os quais motivam os estudantes com desafios, curiosidade, interação e fantasia. Segundo Balasubramanian (BALASUBRAMANIAN et al., 2006, citados por SAVI; ULBRICHT, 2008), os jogos digitais têm a capacidade de estimular o aprendizado em diferentes áreas do conhecimento.

Os jogos educacionais digitais necessitam atender necessidades de cunho pedagógico, e podem ser utilizados desde a educação básica a cursos de graduação. Os jogos educacionais digitais trazem benefícios para a aprendizagem, tais como: motivação, facilidade no aprendizado, desenvolvimento de habilidades cognitivas, descoberta de aprendizagem, estímulo à descoberta, oportunidade de experiências com atividades novas, estímulo à socialização (quando jogadores trabalham em equipes, e até mesmo quando estão competindo), promovem também habilidades motoras, de concentração e de raciocínio, entre outras. Estas vantagens tornam o jogo educacional digital um auxílio didático eficiente (SAVI; ULBRICHT, 2008). 


\section{JOGO IMPLEMENTADO}

Este trabalho apresenta o desenvolvimento de um protótipo de jogo educacional digital, para séries iniciais do Ensino Fundamental, buscando conscientizar as crianças sobre a importância da reciclagem no dia a dia, dentro do contexto da Educação Ambiental. O jogo não se propõe a ser somente um material didático, mas uma ferramenta para o professor estimular a aprendizagem, tornando as atividades pedagógicas mais atrativas e motivadoras, por meio de uma interface gráfica que desperte a atenção e motive os alunos.

O protótipo de jogo educacional digital "Fredi no Mundo da Reciclagem" constitui-se em um jogo com diferentes níveis, tentando dificultar em cada um deles. $\mathrm{O}$ jogo contém regras, cronômetro e contador de acertos, incentivando a criança a manter o foco no mesmo, além de estimular o aprendizado sobre a reciclagem. Os jogos de regras são combinações sensório-motoras (corridas, jogos com bolas) ou intelectuais (cartas, xadrez), em que há competição dos indivíduos (sem o que a regra seria inútil), regulamentadas por um código transmitido de geração em geração ou por acordos momentâneos (PIAGET, 1971 citado por VENÂNCIO, 2008).

A metodologia utilizada neste trabalho foi a dissertação-projeto, pois desenvolveu-se um protótipo de jogo educacional digital. Segundo Ribeiro \& Zabadal (2010), na metodologia de dissertação-projeto, “...o pesquisador caracteriza determinado problema de algum aspecto técnico. Destaca a relevância de resolver esse problema. Desenvolve, então, um programa sistema ou mesmo um protótipo - para apresentar como prova de conceito da solução desse problema" (p. 96).

A modelagem do jogo educacional digital "Fredi no Mundo da Reciclagem" envolveu a definição de interfaces, regras e níveis do mesmo, onde foram definidos o personagem, os elementos gráficos, bem como a estória do mesmo.

O jogo possui um personagem principal, chamado "Fredi" que é conduzido pelo jogador por meio de comandos realizados via teclado do computador. Este nome foi escolhido a partir do nome da cidade onde está localizado o campus da UFSM (Universidade Federal de Santa Maria), a qual pertencem o Curso e o Departamento dos autores deste trabalho - cidade de Frederico Westphalen-RS. Este personagem trafega com uma bicicleta para o deslocamento pelos ambientes onde devem ser coletados os lixos encontrados. De acordo com os níveis, os ambientes são: o parque como primeiro nível, a praia como segundo nível e o caminho para chegar à escola como terceiro nível. Em todos os níveis os ambientes do jogo o ambiente gráfico conta com 5 (cinco) lixeiras para coleta seletiva de lixo, sendo elas destacadas da seguinte maneira: vermelha (materiais como plástico e isopor), azul (materiais como papel, papelão e cartolina), verde (apenas vidro), marrom (material derivado organicamente) e amarela (metais) (PENSAMENTOVERDE, 2015).

O personagem "Fredi" - que representa o jogador - deve recolher os diferentes objetos que se encontram em diferentes posições (os objetos são aleatórios) e colocá-los na lixeira correta fazendo, assim, a coleta seletiva. Para cada acerto o jogador acumula pontos, até atingir a pontuação necessária para passar para o próximo nível. Caso o jogador não clique na lixeira correspondente ao objeto ou ultrapasse o tempo limite do cronometro, o mesmo perderá uma vida (caso ainda possua vidas), registrando assim o erro e dando continuidade no mesmo nível do jogo. No entanto, caso o jogador tenha perdido suas 3 (três) vidas o jogo será encerrado com uma mensagem de "Tente Novamente!" e o nível deverá ser reiniciado.

O jogo "Fredi no Mundo da Reciclagem", conta com 4 (quatro) níveis diferentes, sendo eles: 
- Nível de Instruções: nesse nível o aluno visualiza imagens explicativas na tela, ressaltando a importância da coleta seletiva do lixo, bem como, as cores das lixeiras e a forma de separação, explicando através de áudio o que cada lixeira deve receber, fornecendo exemplos de lixos através de imagens que posteriormente irão aparecer no jogo e seu tempo de decomposição;

- Nível 1 - nesse nível, o ambiente gráfico é um parque e o nível de dificuldade é iniciante, onde o usuário não fará o controle do personagem via teclado, apenas controlará o tempo de jogo com um cronômetro automático de 150 (cento e cinquenta) segundos que estará na tela, devendo recolher os objetos que estarão posicionados na mesma direção com speed 100 (velocidade com que os objetos se movem na tela), os quais irão colidir com a bicicleta em que o personagem se encontra, paralisando a tela para que ele possa separá-los e colocá-los na lixeira correta dentro desse espaço de tempo. Caso contrário será mostrada uma mensagem de "Tente Novamente!" e o usuário deverá reiniciar o nível. Existe um contador de erros que determina o número de vidas do personagem (3), sendo que, a cada erro, uma vida é descontada. Os acertos da coleta seletiva também são contabilizados e quando a criança atingir 10 (dez) acertos o nível seguinte é desbloqueado;

- Nível 2: Nesse nível, o cenário é o ambiente gráfico de uma praia e o nível de dificuldade é intermediário, onde o usuário fará o controle do personagem "Fredi" utilizando as teclas de direção: seta para cima, seta para baixo, seta para a direita, e seta para esquerda. Com um cronômetro de 150 (cento e cinquenta) segundos posicionado na tela o mesmo deverá recolher os objetos, separar e colocar na lixeira correta dentro desse espaço de tempo, caso contrário o tempo acaba sendo mostrada uma mensagem de "Tente Novamente!" e o usuário deverá reiniciar o nível. Assim como no nível anterior, existe um contador de erros que determina o número de vidas (3) e os acertos da coleta seletiva também são contabilizados; neste nível são necessários 15 acertos.

- Nível 3: Nesse nível, o ambiente gráfico é o caminho que Fredi percorre para chegar até a escola e o nível de dificuldade é avançado, onde o usuário fará o controle do personagem nas 4(quatro) possíveis direções através das teclas de direção via teclado, com um cronômetro de 130 (cento e trinta) segundos, devendo recolher os objetos que estarão em uma velocidade mais rápida e em posições diferentes, separá-los e colocá-los na lixeira correta dentro desse tempo, caso contrário o usuário deverá reiniciar o nível. O número de vidas e de acertos é o mesmo do nível 2.

O planejamento dos cenários, bem como as ilustrações do cenário que compõem o jogo foram realizadas por meio de um storyboard. O storyboard permite representar um rascunho do projeto gráfico da aplicação, auxiliando na organização e disposição dos elementos. As telas do storyboard são representadas por quadros chamados frames, onde cada quadro deve mostrar o que está contido na respectiva tela. O storyboard é o "rascunho" da aplicação permitindo aos responsáveis pelo projeto visualizarem sua estrutura de navegação, ou seja, discutirem a sequência do conteúdo e fazerem as revisões e o acompanhamento necessários (FALKEMBACH et al., 2005).

A interface inicial, apresenta o personagem principal chamado "Fredi", destacando o nome do jogo e do personagem. A interface apresenta de forma divertida 
uma breve introdução sobre a Educação Ambiental, em forma gráfica, mostrando um mundo menos poluído e com preservação ambiental. O personagem é o responsável por fazer as coletas dos objetos que encontrar nos diferentes cenários e separá-los adequadamente.

O protótipo foi desenvolvido utilizando-se a ferramenta Construct 2, a qual facilita o desenvolvimento de jogos em HTML5 (HyperText Markup Language), sem que seja necessário o conhecimento de uma linguagem de programação específica. A ferramenta Construct 2 é uma base poderosa para criar jogos HTML5, projetados especificamente para jogos 2D, possibilitando construir jogos sem necessidade de codificação (SCIRRA, 2016).

A Figura 1 apresenta a tela inicial do jogo, a qual possui a imagem do personagem Fredi, bem como o botão de acesso ao jogo (representando pelo símbolo de play) e o botão de instruções (representado pela letra $i$ ). Nessa tela tem-se um áudio dando as boas-vindas ao jogador.

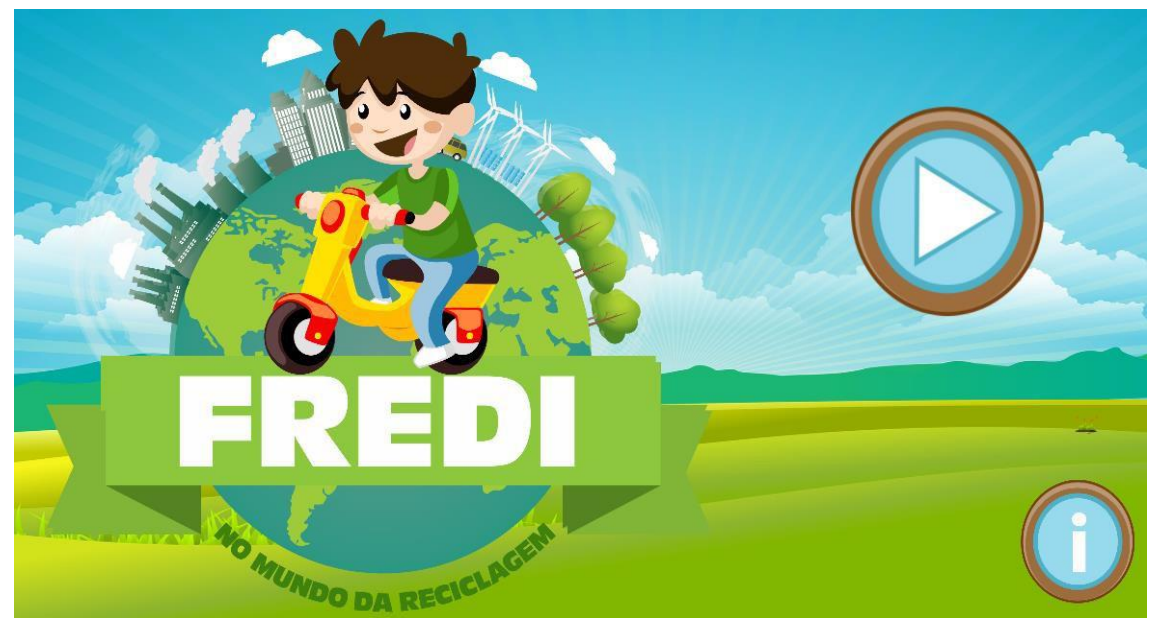

Figura 1: Tela Inicial do jogo, "Fredi no Mundo da Reciclagem" (Fonte: dos autores, 2016)

No nível de instruções do jogo, conforme Figura 2, são apresentadas imagens que relacionam objetos diversos encontrados no jogo "Fredi no Mundo da Reciclagem" e as suas respectivas lixeiras, para que seja realizada a coleta seletiva de forma adequada.

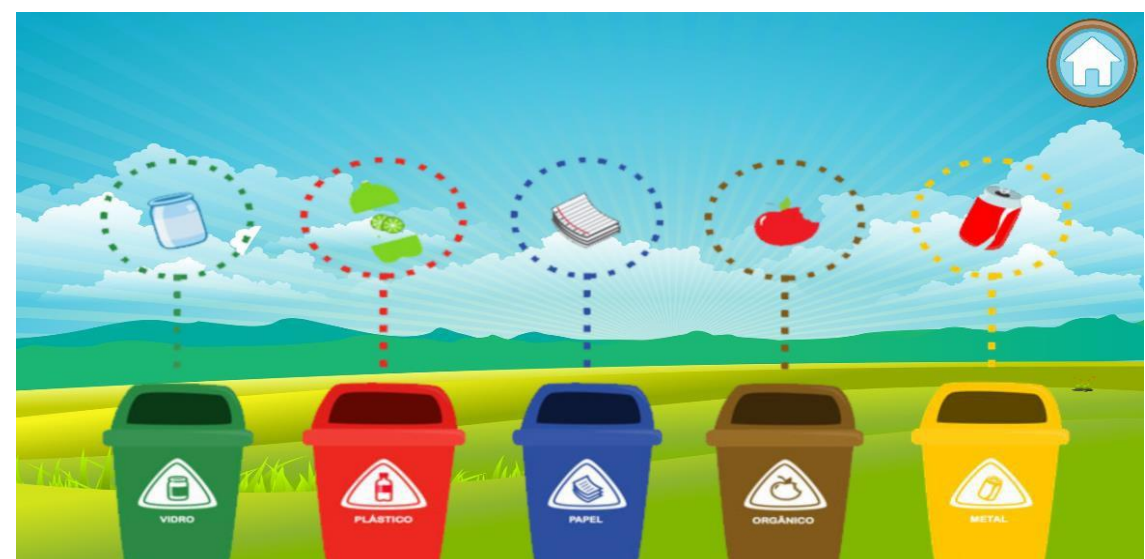

Figura 2: Nível de Instruções do jogo, "Fredi no Mundo da Reciclagem" (Fonte: dos autores, 2016)

No Nível 1, por meio do cenário de um Parque, conforme mostra a Figura 3, o personagem Fredi movimenta-se por meio da animação de frames em sua bicicleta, 
porém permanece imóvel em sua posição na tela. Os objetos (lixos) diversos vêm ao encontro do personagem de forma aleatória e, ao colidir com a bicicleta, a tela é pausada automaticamente até que o jogador identifique e realize a coleta seletiva, clicando na lixeira correta, a qual aparecerá na tela no momento da colisão. Em caso de acerto uma mensagem gráfica é apresentada ao jogador representando um acerto (símbolo " $\checkmark "$ ) e o contador é incrementado, apresentando o número de acertos que ainda faltam e destruindo o objeto em questão. Já em caso de erro, uma mensagem gráfica é apresentada (símbolo "X") que simboliza o erro e uma vida das 3 (três) é descontada. As vidas são representadas por ícones no formato de coração, localizados no topo esquerdo da tela.

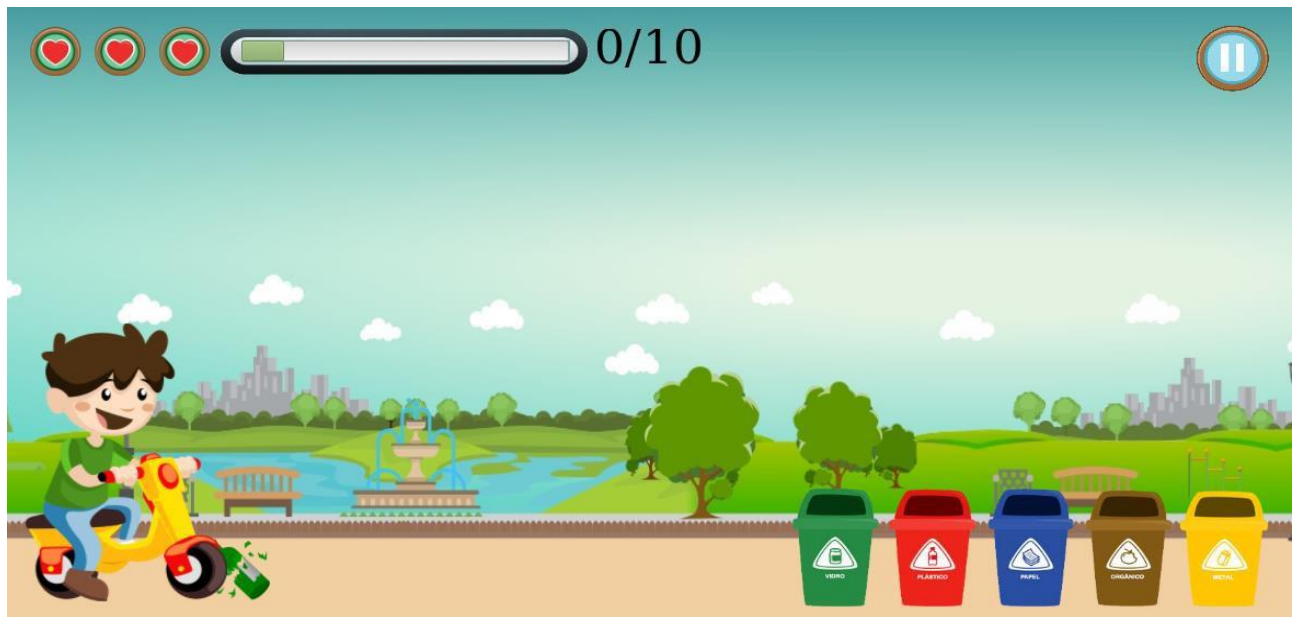

Figura 3: Tela do primeiro nível do jogo, "Fredi no Mundo da Reciclagem" (Fonte: dos autores, 2016)

O nível 2, representado por meio do cenário da praia, conforme Figura 4, permite a utilização das setas de direção via teclado para movimento do personagem. Nesse nível o usuário pode ir ao encontro do objeto que virá de forma aleatória e em diferentes posições na tela. Quando a bicicleta colidir com o objeto a tela será pausada, porém com o cronômetro ainda ativo, até que o usuário faça a seleção da lixeira adequada, clicando na mesma. O objeto só poderá ser classificado quando colidir com a bicicleta, assim tornando visíveis as lixeiras para coleta seletiva. As mensagens gráficas de acerto e erro são exibidas conforme a situação e um áudio correspondentes à situação é executado. Durante o jogo o usuário pode solicitar "pausa" clicando na imagem do canto superior direito da tela. Neste caso o jogo irá parar automaticamente e só será reiniciado quando o usuário clicar novamente em play. O desbloqueio do nível seguinte é feito por meio do número de acertos necessários, ou seja, 15 (quinze) acertos, sem que se percam as 3 (três) vidas, lembrando que o jogo permite a perda de 2 (duas) das 3(três) vidas. 


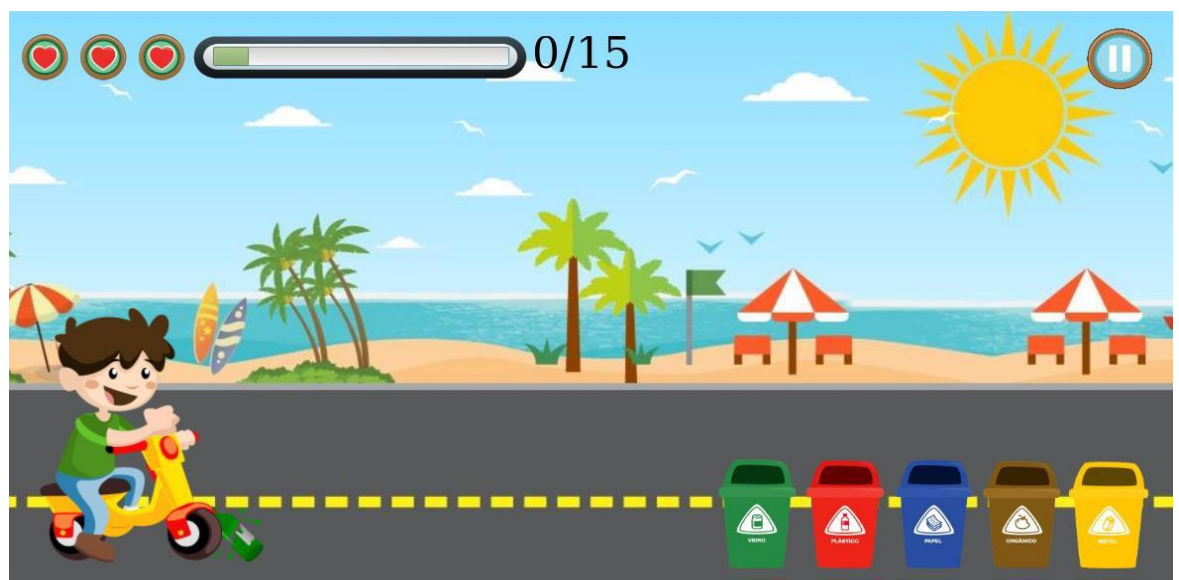

Figura 4: Tela do Segundo nível do jogo, "Fredi no Mundo da Reciclagem" (Fonte: dos autores, 2016)

O último nível do jogo (nível 3), conforme mostra a Figura 5, é representado por meio do cenário do caminho do personagem Fredi para a escola. Neste cenário, assim como no nível 2, o personagem Fredi move-se por meio de ações do usuário via teclado (setas de direção). Os objetos, posicionados de forma aleatória, vem ao encontro do personagem e, ao colidir com a bicicleta, assim como nas demais fases, fazem com que a tela seja paralisada e as lixeiras tornem-se visíveis até a coleta seletiva ser realizada pelo jogador por meio de um clique no mouse. Nesse nível a dificuldade aumenta, pois o cronômetro é de 130 (cento e trinta) segundos e o número de acertos mantém-se em 15 (quinze).

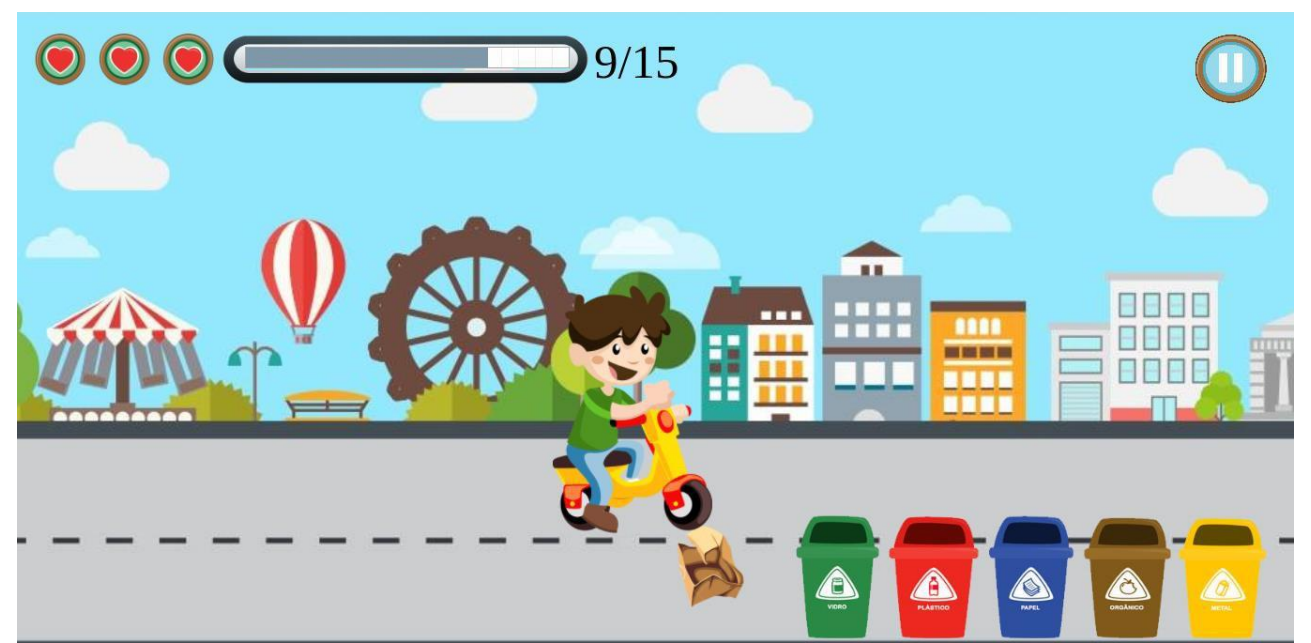

Figura 5: Tela do Terceiro nível do jogo, "Fredi no Mundo da Reciclagem" (Fonte: dos autores, 2016)

\subsection{TESTES E VALIDAÇÃO}

Durante o desenvolvimento do protótipo foram realizados vários testes, a fim de verificar se todas as suas funcionalidades estavam sendo executadas corretamente, bem como verificar se o nível do jogo é apropriado para a faixa etária escolhida, além de buscar a cada teste melhoria em seu desenvolvimento. Os testes foram feitos durante o desenvolvimento, pelos próprios autores, sendo observadas possíveis melhorias.

A validação contou com o apoio da Escola Municipal de Ensino Fundamental Afonso Balestrin da cidade de Taquaruçu do Sul -RS e do Colégio Nossa Senhora Auxiliadora de Frederico Westphalen - RS, no dia 22 de novembro de 2016, e contou 
com a participação de 22 (vinte e dois) alunos sendo eles 11 (onze) meninas e 11 (onze) meninos, todos do $4^{\circ}$ (quarto) ano do Ensino Fundamental, os quais, juntamente com a professora responsável foram até o laboratório de informática e, em duplas separadas por gênero, organizadas pelos próprios alunos, efetuaram o teste do jogo. Os alunos jogaram em duplas já que o laboratório possui 19 (dezenove) computadores estando 16 em funcionamento, além de um computador para a professora da turma. Todos os computadores do laboratório eram antigos com Internet muito lenta e não possuíam saída de som, o que impediu o teste de áudio do jogo, mesmo assim os alunos conseguiram jogar normalmente utilizando o Google Chrome. Cabe destacar que todos os procedimentos éticos para a participação dos alunos foram seguidos.

Durante a validação, os autores, além de acompanhar e auxiliar as crianças na utilização do jogo, também preencheram um roteiro de observação. Além disso, foi aplicado um instrumento para coletar as impressões da professora sobre o protótipo implementado. Ao perguntarmos se os alunos haviam mostrado interesse na atividade proposta pelo jogo, a professora destacou, que sim, pelo desafio encontrado e por saberem sobre a separação do lixo. Quando questionada sobre a relevância do jogo educacional desenvolvido para o auxílio nos processos de ensino e de aprendizagem na área de Educação Ambiental, a professora afirmou que é importante o desenvolvimento do jogo para que as crianças aprendam separar de maneira correta o lixo de seu dia a dia: "Essa tecnologia vem a contribuir e aprimorar os conteúdos curriculares, fazendo com que os alunos aprendam e fixem de maneira prazerosa". Ao finalizar o período de validação (aproximadamente 45 minutos) perguntou-se aos alunos sugestões de melhoria para o jogo, onde os mesmos acharam desnecessárias possíveis melhorias. A Figura 6 apresenta uma foto da validação realizada na Escola Afonso Balestrin. Cabe destacar que a escola possui autorização dos pais e/ou responsáveis para utilizar as imagens dos alunos. Mesmo assim, preferiu-se que os rostos dos mesmos não aparecessem nas fotos.

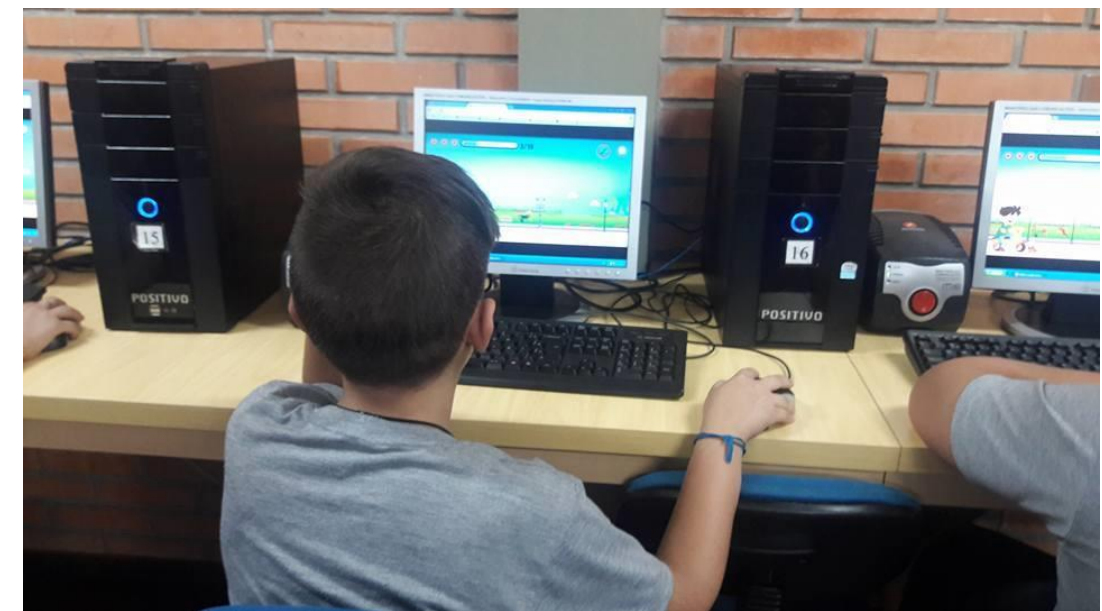

Figura 6: Validação do jogo na escola de Taquaruçu do Sul. (Fonte: dos autores, 2016)

A validação no Colégio Nossa Senhora Auxiliadora de Frederico Westphalen RS aconteceu no dia 01 de dezembro de 2016, e contou com a colaboração das turmas do $2^{\mathrm{a}}$ ano $\mathrm{A}$ e $\mathrm{B}$, e a turma do $4^{\mathrm{o}}$ ano do Ensino Fundamental. O laboratório de Informática conta com 12 (doze) computadores para acesso dos alunos estando todos em funcionamento, e um computador para a professora de informática, todos utilizando o sistema operacional Microsoft Windows. O teste do jogo foi realizado usando o navegador Google Chrome e, diferentemente da escola anterior, pôde ser utilizado a execução dos áudios pois todos os computadores possuíam caixa de som. O som foi 
utilizado na primeira validação de uma das turmas e, nas demais, optou-se por desligar as caixas de som, a fim de diminuir o barulho na sala de informática. Participaram da validação a turma do $2^{\circ}$ ano $\mathrm{A}$, com 18 (dezoito) alunos, sendo 11 (onze) meninos e 7 (sete) meninas. Observou-se que os mesmos encontraram dificuldade para classificar o lixo por cor de lixeira, demorando para realizar a leitura na imagem de cada lixeira para classificação do tipo de material depois da colisão dos objetos. Esta dificuldade não foi observada nas próximas validações, realizadas com a turma do $2^{\circ}$ ano $\mathrm{B}$, com 8 (oito) meninos e 9 (nove) meninas e com a turma do $4^{\circ}$ ano, com 8 (oito) meninos e 13 (treze) meninas.

Todos os alunos das referidas turmas foram conduzidos pela professora responsável até o laboratório em tempos separados de aproximadamente 40 (quarenta) minutos e as validações foram acompanhadas pela equipe de desenvolvimento. Os autores auxiliaram os alunos durante a validação, sendo que os alunos demonstraram interesse e entusiasmo ao jogar. A maioria dos alunos ficou dividida em duplas para que todos pudessem testar o jogo. Notou-se que os mesmos dividem-se em duplas por gêneros (meninos com meninos e meninas com meninas).

Ao final da validação perguntou-se aos alunos se os mesmos tinham sugestões que pudessem melhorar o jogo. Os alunos do $2^{\circ}$ ano sugeriram que o personagem Fredi pudesse se mover mais rapidamente em direção aos lixos, ou seja, que fosse possível aumentar a velocidade via teclado pela seta de direção da direita, além de sugerirem que o tempo do cronômetro fosse menor, dificultando ainda mais o jogo.

A dificuldade que observamos durante a validação foi a identificação de alguns objetos de coleta (lixos) como o caso do "papel amassado" que alguns alunos consideravam que era metal. Ao término da validação perguntamos aos alunos quais seriam as sugestões de melhoria do jogo, e os mesmos nos pediram o desenvolvimento de mais fases, sendo que alguns acharam o jogo simples e outros consideraram o jogo complexo. Os que consideram o jogo complexo sugeriram o aumento do tempo do cronômetro. Outra sugestão de uma das alunas foi diminuir o número de lixos, pois a mesma achou muito lixo para recolher em cada uma das fases. Notou-se, na turma do $4^{\circ}$ ano, que alguns alunos procuravam por possíveis falhas no jogo, mostrando noções de conhecimento em informática, pois utilizavam a denominação bug.

\section{CONSIDERAÇÕES FINAIS}

Acredita-se que os objetivos deste trabalho tenham sido atingidos com sucesso, já que foi possível estudar as técnicas para melhor aproveitamento da ferramenta Construct 2, bem como estudar os conceitos de Educação Ambiental voltados à reciclagem. Além disso, aprofundou-se o conhecimento dos jogos digitais com cunho educacional, visando desenvolver um jogo útil para o ensino da reciclagem, bem como a modelagem do jogo educacional digital proposto foi definida, detalhando-se as fases e o storyboard do mesmo.

Com base nos resultados das validações, pode-se observar que a ferramenta desenvolvida poderá auxiliar educadores nos processos de ensino e de aprendizagem sobre a reciclagem em séries iniciais, mostrando a importância das ferramentas digitais para uma educação mais ampla e de qualidade.

Uma das dificuldades foi a de desenvolver um jogo com regras e nível de dificuldade adequado, somente analisando como uma criança na faixa etária de 7 (sete) a 9 (nove) anos se motivaria e interpretaria o uso do jogo como forma de aprendizagem, buscando motivá-las ainda mais a jogar. Desse modo, a modelagem do jogo teve que 
ser planejada de acordo com a idade e o com nível de dificuldade que fosse condizente com a idade escolhida para o protótipo. Além disso, a definição das interfaces gráficas, teve que ser planejada e analisada para que as cores e a disposição dos objetos permitissem a criação de um ambiente agradável. Um estudo de produção sonora para os efeitos de som também se fizeram presente para o desenvolvimento do trabalho, auxiliando as crianças por meio da fala e tornando o jogo ainda mais lúdico com fundo musical.

Para trabalhos futuros propõe-se a implementação de uma segunda versão do jogo, com a ampliação de objetos para a coleta seletiva, bem como ampliar o número de fases, dessa forma dificultando ainda mais o jogo. Uma das sugestões das professoras que acompanharam a validação nas escolas foi o desenvolvimento de um quarto nível, onde as lixeiras deveriam ser escolhidas para a classificação da coleta seletiva apenas pelas cores, retirando a escrita na imagem das lixeiras, assim podendo também ser usados para outras faixas etárias. Sugere-se para uma versão futura a utilização da função Drag and Drop (Arrastar-Soltar), para a seleção dos objetos e coleta seletiva, ou seja, arrastar os objetos e soltá-los sobre a lixeira correta. O jogo está disponível para acesso via $w e b$ no link $<$ https://angelicaskalee.github.io/fredi/>.

\section{REFERÊNCIAS}

BRASIL (1999). Lei 9795 de 27 de abril de 1999: dispõe sobre a educação ambiental, institui a política nacional de educação ambiental e dá outras providências. Disponível em: <http://www.planalto.gov.br/ccivil_03/leis/L9795.htm>. Acesso em abril, 2016.

COX; K. K. (2003) Informática na Educação Escolar. Coleção Polêmica do Nosso Tempo, 87. Campinas, SP. Autores Associados, Agosto 2003.

FALKEMBACH, G. A. M. (2005). Concepção e Desenvolvimento De Material Educativo Digital. RENOTE: Revista Novas Tecnologias na Educação. CintedUFRGS, V. 3 No 1, Maio, 2005. Disponível em: $<$ http://seer.ufrgs.br/renote/article/view/13742/7970>. Acesso em junho, 2016.

PARREIRA, F. J.; FALKEMBACH, G. A. M.; SILVEIRA S. R. (2016). Construção de Jogos Educacionais Digitais e Objetos de Aprendizagem: Um estudo de caso empregando Adobe Flash, HTML 5, CSS, JavaScript e Ardora. Rio de Janeiro: Ciência Moderna. No prelo.

PENSAMENTO VERDE (2015). Cores das lixeiras para separação do lixo reciclável. Pensamento Verde. 06 de Janeiro de 2015. Disponível em: $<$ http://www.pensamentoverde.com.br/reciclagem/cores-das-lixeiras-para-separacaolixo-reciclavel/\#>. Acesso em junho de 2016.

REIS, J. R.; MACHADO, D. S. P.; FONSECA, W. S. (2012). Fabricação de Jogos a partir de Materiais Recicláveis como Meio de Conscientização e Responsabilidade Socioambiental. Anais do COBENGE - XL Congresso Brasileiro de Educação em Engenharia. Belém - PA: ABENGE. Disponível em: $<$ http://www.abenge.org.br/CobengeAnteriores/2012/artigos/104046.pdf $>$. Acesso em abril, 2016. 
RIBEIRO, V. G.; ZABADAL, J. R. S. (2010). Pesquisa em Computação: uma abordagem metodológica para trabalhos de conclusão de curso e projetos de iniciação científica. Porto Alegre: Editora UniRitter.

SAVI, R.; ULBRICHT, V.R. (2008) Jogos Digitais Educacionais: Benefícios e Desafios. RENOTE: Revista Novas Tecnologias na Educação. Cinted-UFRGS, v. 6, n. 2, Dezembro de 2008. Disponível em: $<$ http://seer.ufrgs.br/renote/article/view/14405/8310>. Acesso em 11 de abril de 2016.

SCIRRA (2016). Construct 2. Disponível em: <https://www.scirra.com/construct2>. Acesso em junho de 2016.

VENÂNCIO, M.C. (2008) Jogar aprendendo: Contribuições dos jogos no processo de letramento. Universidade Candido Mende. São Paulo. Disponível em: $<$ http://www.avm.edu.br/docpdf/monografias publicadas/posdistancia/35398.pdf $>$. Acesso em 17 de maio de 2016. 